\title{
Структура и свойства полученных методом магнетронного распыления тонких графитоподобных пленок
}

\author{
(C) А.Я. Виноградов ${ }^{1}$, С.А. Грудинкин ${ }^{1, \uparrow}$, Н.А. Беседина ${ }^{2}$, С.В. Коняхин ${ }^{1,2}$, М.К. Рабчинский ${ }^{1}$, \\ Е.Д. Эйдельман ${ }^{1,3}$, В.Г. Голубев ${ }^{1}$ \\ ${ }^{1}$ Физико-технический институт им. А.Ф. Иоффе Российской академии наук, \\ 194021 Санкт-Петербург, Россия \\ ${ }^{2}$ Санкт-Петербургский национальный исследовательский академический университет \\ Российской академии наук, \\ 194021 Санкт-Петербург, Россия \\ ${ }^{3}$ Санкт-Петербургская государственная химико-фрармацевтическая академия, \\ 197376 Санкт-Петербург, Россия \\ ฯ E-mail: grudink.gvg@mail.ioffe.ru
}

(Получена 30 ноября 2017 г. Принята к печати 4 декабря 2017г.)

\begin{abstract}
Исследованы структурные, электрические и оптические свойства тонких графитоподобных пленок, полученных на кристаллическом кремнии и кварце методом магнетронного распыления при температурах подложки в диапазоне от 320 до $620^{\circ} \mathrm{C}$. Из анализа спектров комбинационного рассеяния света установлено, что с ростом температуры подложки происходит увеличение характерного размера кристаллитов, уменьшение концентрации структурных дефектов и содержания аморфного углерода в фазовом составе пленок. С увеличением температуры подложки в спектрах оптического поглощения в ультрафиолетовой области спектра наблюдался сдвиг максимума интенсивности поглощения в область бо́льших длин волн и возрастание поглощения в видимой и ближней ИК-областях спектра. С ростом температуры осаждения удельная электропроводность пленок увеличивалась с $0.2 \mathrm{OM}^{-1} \cdot \mathrm{cm}^{-1}$ при $320^{\circ} \mathrm{C}$ до $30 \mathrm{OM}^{-1} \cdot \mathrm{cm}^{-1}$ при $620^{\circ} \mathrm{C}$.
\end{abstract}

DOI: $10.21883 /$ FTP.2018.07.46051.8782

\section{1. Введение}

Одним из приоритетных направлений современной энергетики является поиск новых конструкций термоэлектрических генераторов, которые позволят добиться повышения их термоэлектрической эффективности. В патенте [1] предложена идея конструкции термоэлектрического преобразователя на основе углеродной наноструктуры, состоящей из чередующихся плоских слоев с $s p^{2}$-гибридизацией атомов углерода (графитоподобные области с металлическими свойствами) и слоев c $s p^{3}$-гибридизацией атомов углерода (алмазоподобные области с диэлектрическими свойствами). В такой наноструктуре может быть получен как эффект увлечения электронов баллистическими фононами, так и эффект уменьшения теплопроводности за счет теплоотдачи на границах областей с различным типом гибридизации электронных оболочек [2-4]. Это может позволить достичь величины термоэлектрической эффективности $\sim 150$. Как один из возможных вариантов для создания $s p^{2}$-слоев, предлагается использовать тонкие (толщиной 10-50 нм) пленки графитоподобного углерода. В качестве $s p^{3}$-слоев предлагается использовать алмазные пленки толщиной 100-300 нм.

Прогресс в области синтеза алмазных пленок методом химического газофазного осаждения (CVD) позволяет рассматривать этот метод как перспективный для нанесения слоев с $s p^{3}$-гибридизацией атомов углерода при создании термоэлектрического преобразователя на основе углеродных наноструктур. В различных способах получения слоев графитоподобного углерода с высоким кристаллическим совершенством температуры синтеза или последующего отжига обычно составляет приблизительно $1000^{\circ} \mathrm{C}[5,6]$. Эта температура превышает типичную температуру CVD роста алмазных пленок [7,8] и частиц на разных подложках $[9,10]$, что может привести к изменениям фазового состава и нарушениям механических свойств $s p^{3}$-слоя из-за термического воздействия в процессе осаждения на него $s p^{2}$-слоя. Для достижения технологической совместимости процессов осаждения чередующихся слоев с $s p^{3}$ - и $s p^{2}$-гибридизацией атомов углерода необходимо развить метод получения $s p^{2}$-слоев при температурах, не превышающих используемые в процессе CVD синтеза $s p^{3}$-слоев. В данной статье описываются результаты исследования свойств и структуры тонких пленок графитоподобного углерода, полученных методом магнетронного распыления при температурах подложки, не превышающих $620^{\circ} \mathrm{C}$.

\section{2. Методика эксперимента}

Пленки графитоподобного углерода осаждались на подложки из кристаллического кремния и кварца методом магнетронного распыления графитовой мишени в режиме постоянного тока. Материал мишени - мелкозернистый плотный графит марки 6516pТ (Мерсен, Франция). Диаметр мишени 60 мм. Размер нагреваемого держателя подложки $-70 \times 70$ мм. Рабочий газ в процессе распыления - аргон. Давление аргона 1.6 мТорр. 

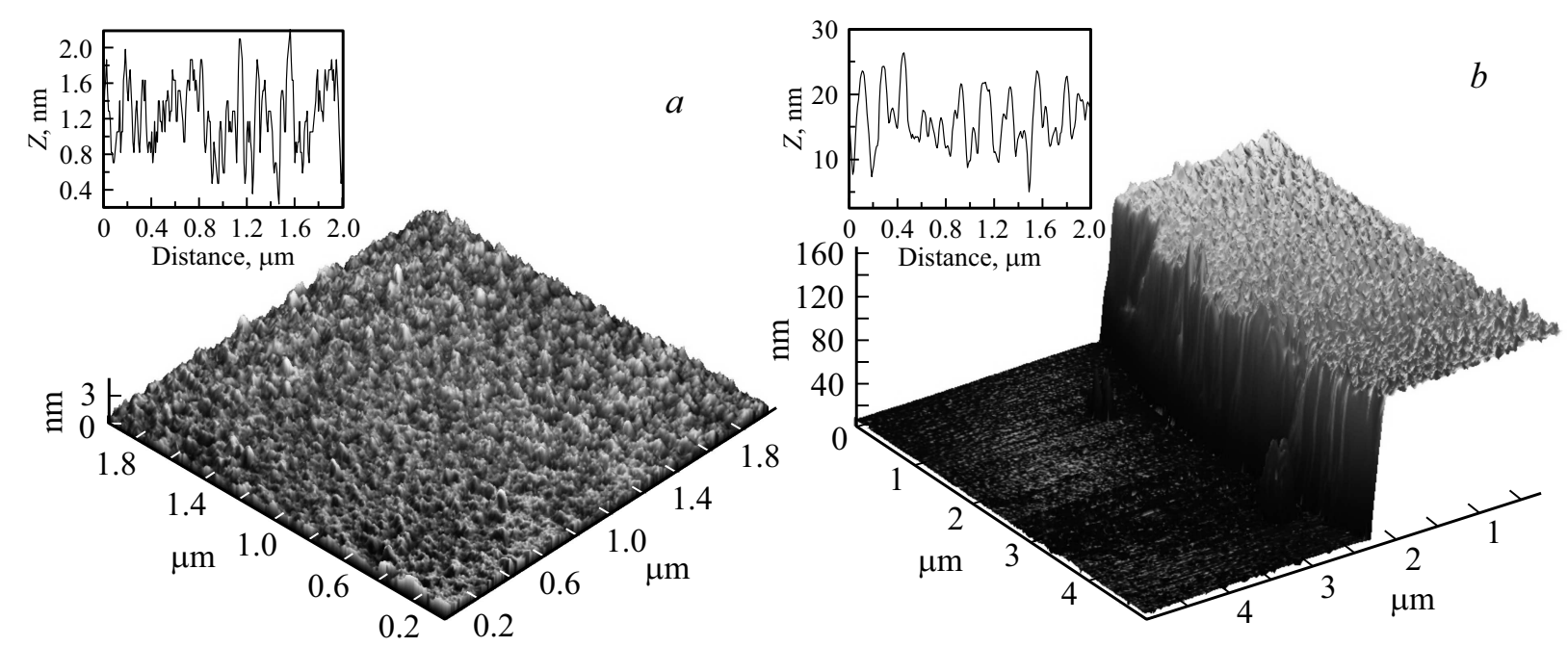

Рис. 1. Трехмерное СЗМ-изображение поверхности графитоподобной пленки, полученной при температуре подложки $320^{\circ} \mathrm{C}(a)$, и сечение профиля ступени между подложкой и графитоподобной пленкой, полученной при температуре $620^{\circ}(b)$. На вставках приведены профили сечения поверхности пленок.

Ток разряда 200 мА. Температура подложки варьировалась от 320 до $620^{\circ} \mathrm{C}$.

Исследования топографии поверхности проводились с помощью сканирующего зондового микроскопа „Смена“ (NT-MDT) в атмосферных условиях полуконтактным методом. Толщина пленок оценивалась по профилю следа скрайбирования с помощью сканирующего зондового микроскопа.

Спектры комбинационного рассеяния света (КРС) измерялись на установке Horiba Jobin Yvon LabRam HR800. Длина волны возбуждающего лазера $532 \mathrm{HM}$, решетка 1800 шт/мм. Лазер фокусировался объективом $20 \times$ в пятно диаметром 20 мкм. Время накопления фрейма 20 с, кратность накопления для усреднения 20 фреймов.

Спектры оптической плотности пленок графитоподобного углерода, нанесенных на кварцевые подложки, регистрировались с использованием однолучевого спектрофотометра Shimadzu UV-2450 с диафрагмой диаметром 5 мм в диапазоне длин волн от 200 до 1000 нм, с разрешением 0.5 нм. Все полученные спектры нормировались на известную толщину исследуемой пленки.

Электропроводность графитоподобных пленок была рассчитана исходя из определенных величин удельного сопротивления. Измерения сопротивления проводились при комнатной температуре с использованием четырехзондового метода с линейным расположением прижимных зондов из золота. Величины удельного сопротивления определялись в результате усреднения значений, полученных для пяти разных областей в каждой пленке.

\section{3. Экспериментальные результаты и их обсуждение}

На рис. 1 представлены трехмерные изображения поверхности графитоподобных пленок, осажденных при температуре подложки 320 и $620^{\circ} \mathrm{C}$. Изображения получены в области сканирования $2 \times 2$ мкм. На вставках к рис. 1 приведены сечения профиля поверхности пленок. Среднеквадратичные шероховатости поверхности исследуемых пленок составляют: $0.4 \mathrm{HM}\left(320^{\circ} \mathrm{C}\right), 0.54 \mathrm{Hм}$ $\left(420^{\circ} \mathrm{C}\right), 2.4 \mathrm{Hм}\left(510^{\circ} \mathrm{C}\right), 4.4 \mathrm{Hм}\left(620^{\circ} \mathrm{C}\right)$.

Для определения толщины пленки методом скрайбирования стальной иглой создавались царапины глубиной до поверхности подложки с резким профилем краев (рис. $1, b)$. Измерение топографии поверхности кремниевой подложки после удаления пленки показало, что при процедуре скрайбирования поверхность кремния не повреждалась. Толщина пленки определялась из измерения профиля ступени между пленкой и подложкой (рис. $1, b$ ). Толщины пленок находились в диапазоне 40-100 нм.

На рис. 2 показаны экспериментальные спектры КРС исследуемых пленок в области первого порядка (с участием одного фонона) и результаты разложения их спектрального контура. Спектры пленок, полученных при температурах подложки $320-520^{\circ} \mathrm{C}$, раскладывались на четыре линии, обозначаемые в литературе $G, D 1(D)$, $D 3, D 4\left(D^{\prime \prime}\right)$ [11-13]. Спектр пленки, полученной при $620^{\circ} \mathrm{C}$, раскладывался на пять линий: $G, D 1, D 3, D 4$ и линию $D 2\left(D^{\prime}\right)$. В соответствии с методикой, предложенной в работах $[11,12]$, для аппроксимации линий $G$, $D 1, D 2, D 4$ использовался контур Лоренца, а для линии $D 3$ - контур Гаусса. Линия $G$ в области $1580 \mathrm{~cm}^{-1}$ соответствует нерезонансному рассеянию света с участием оптического фонона симметрии $E_{2 g}$ вблизи точки Г зоны Бриллюэна $[13,14]$. Полоса $D$ в области $1350 \mathrm{~cm}^{-1}$ возникает в результате двойного резонансного рассеяния с участием электронных состояний из двух неэквивалентных $K$ - и $K^{\prime}$-точек зоны Бриллюэна и оптического фонона $A_{1 g}$ симметрии [14]. Соблюдение правила отбора по квазиимпульсу в этом процессе обеспечивается участием дефекта кристаллической решетки. Наличие 

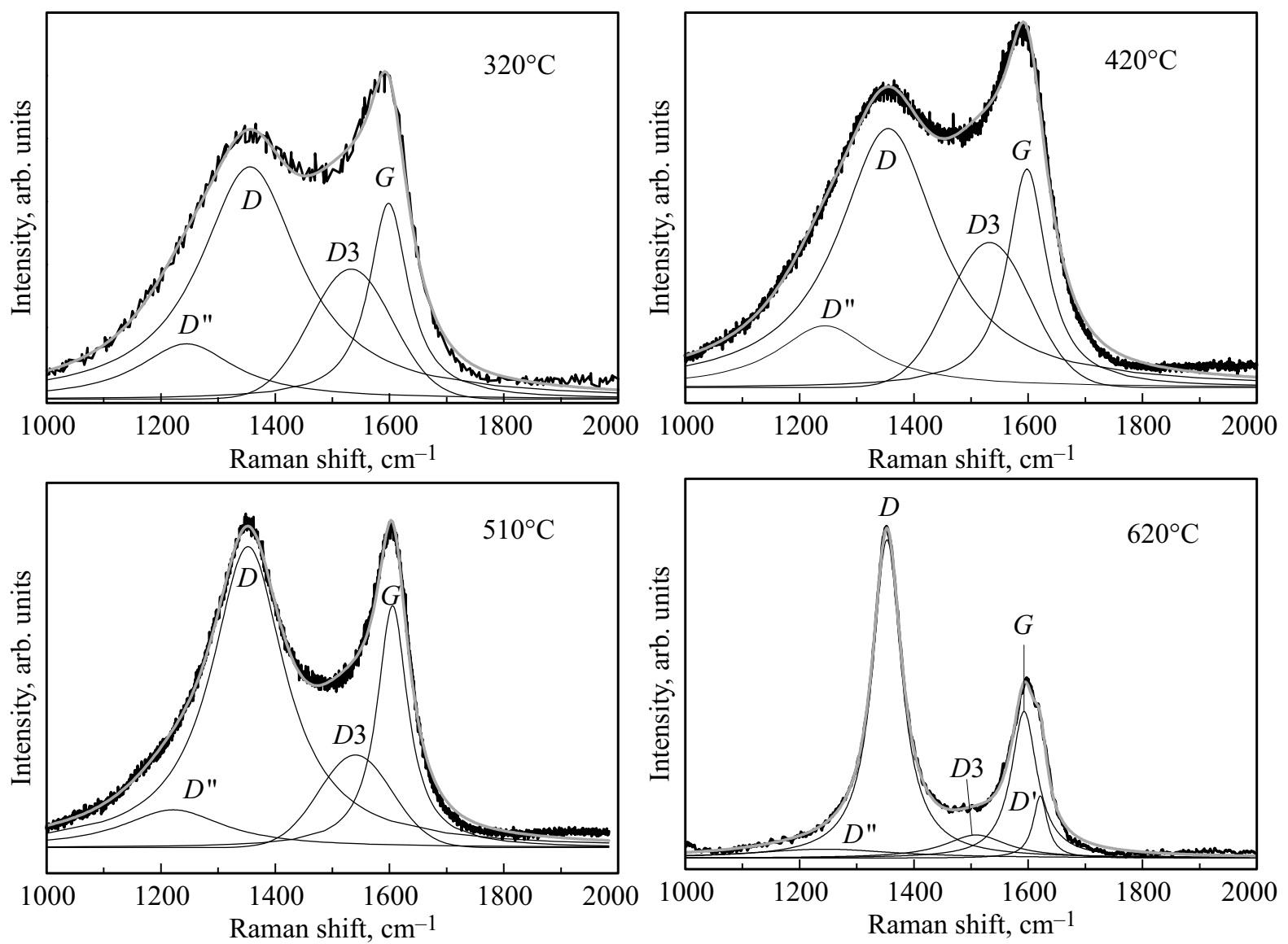

Рис. 2. Спектры КРС графитоподобных пленок, осажденных при различных температурах подложки, и результаты разложения их спектрального контура.

полосы $D 2$ в области $1620 \mathrm{~cm}^{-1}$ объясняется двойным резонансом с участием двух электронных состояний на дираковском конусе вблизи точки $K$ (или $K^{\prime}$ ) зоны Бриллюэна (внутридолинный процесс) $[13,15]$. Правило отбора по квазиимпульсу в этом процессе выполняется за счет участия в нем дефекта кристаллической решетки. Полосы $D 1$ и $D 2$ обусловлены присутствием дефектов в графеновых слоях. Под графеновым слоем мы понимаем слой соединенных в гексагональную двумерную решетку $s p^{2}$ гибридизованных атомов углерода толщиной в один атом, находящийся внутри углеродного материала, безотносительно того имеет ли он трехмерное упорядочение [16]. Широкая полоса $D 3$ в области частоты $1500 \mathrm{~cm}^{-1}$ связана с присутствием в составе материала пленки аморфного углерода $[11,17]$. Полоса $D 4$ в области $1200 \mathrm{~cm}^{-1}$ обусловлена двойным резонансным рассеянием, в процессе которого участвует дефект кристаллической решетки [18].

На рис. 3 приведены зависимости отношения интегральной интенсивности полос $G$ и $D\left(I_{D} / I_{G}\right)$, значений их полной ширины на половине высоты (ПШПВ, $F(H M)$, а также спектрального положения максимума полосы $G$ в спектрах КРС графитоподобной пленки от температуры осаждения, полученные из анализа разложения спектров КРС. С увеличением температуры подложки происходит сужение $G$ и $D$ линий. Зависимости $I_{D} / I_{G}$ и спектрального положения полосы $G$ от температуры подложки имеют максимум в диапазоне температур $400-500^{\circ} \mathrm{C}$. Эти зависимости спектра КРС могут быть объяснены с учетом так называемой феноменологической трехстадийной модели - „аморфизационной траектории“, предложенной в работе [19].

На первой стадии с ростом структурного беспорядка в материале происходит переход кристаллического графита в нанокристаллический графит [19]. На этой стадии с увеличением беспорядка положение $G$ полосы сдвигается от 1595 к $1605 \mathrm{~cm}^{-1}$ и растет отношение $I_{D} / I_{G}$ (рис. 3). При этом на этой стадии отношение $I_{D} / I_{G}$ обратно пропорционально размеру кристаллитов в направлении, параллельном базисной плоскости графита $\left(L_{a}\right)[19]$.

На второй стадии с увеличение содержания дефектов структура углеродного материала трансформируется от нанокристаллического графита к аморфному углероду. Спектральное положение $G$ полосы с ростом беспорядка углеродной структуры испытывает низкочастотный сдвиг от 1605 до $1598 \mathrm{~cm}^{-1}$ [19]. Полоса $D$ обусловлена симметричными колебаниями растяжения-сжатия (дышащая мода) в графеновых (графеновых) кольцах. С ростом структурного беспорядка увеличивается кон- 


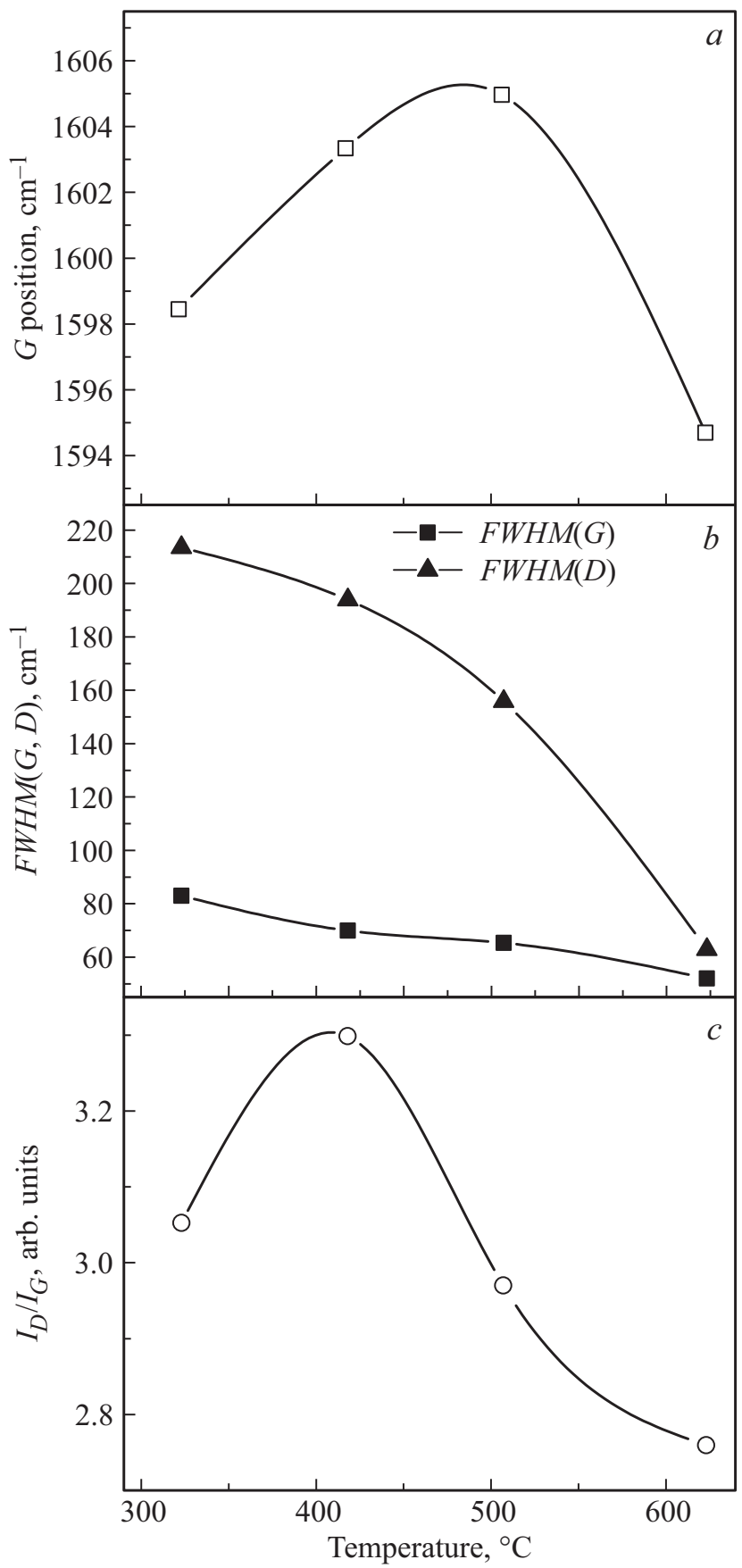

Рис. 3. Зависимости спектрального положения максимума полосы $G(a)$, ПШПВ полос $G$ и $D(b)$, отношения интегральных интенсивностей полос $G$ и $D(c)$ в спектрах КРС графитоподобных пленок от температуры подложки.

центрация дефектов в графеновых кольцах и, в конце концов, кольца размыкаются [20]. В результате интенсивность линии $D$ оказывается очень чувствительной к структурному беспорядку. Линия $G$ связана с валентными колебаниями атомов углерода в кольцах, и ее интенсивность не так чувствительна к беспорядку (нарушению целостности графеновых колец), как линия $D$. Для малых величин $L_{a}$, интенсивность $D$ линии про- порциональна вероятности наличия графенового кольца. При этом отношение $I_{D} / I_{G}$ пропорционально квадрату $L_{a}[20]$.

Анализ в рамках „аморфизационной траектории“ позволяет судить об изменениях структуры материала пленок в зависимости от температуры подложки. Наличие максимумов на графиках зависимости $I_{D} / I_{G}$ (рис. 3) от температуры подложки можно трактовать как переход от второй стадии к первой с ростом температуры подложки, который происходит в диапазоне температур $400-500^{\circ} \mathrm{C}$. С ростом температуры подложки от 320 до $620^{\circ}$ происходит увеличение размера кристаллитов в пленке. Кроме того, наблюдаемое в спектрах КРС понижении интенсивности линии $D 3$ относительно линии $G$ свидетельствует об уменьшении доли аморфного углерода в фазовом составе пленок с ростом температуры подложки. Наблюдаемое уменьшение ПШПВ полос $G$ и $D$ с увеличением температуры подложки (рис. $3, b)$ связано с уменьшением числа структурных дефектов в графеновых слоях. В работе [21] уменьшение ширины полосы $G$ объяснено увеличением характерного размера нанокристаллитов в образцах нанокристаллического графита.

В работе [22] показано, что для кристаллических графитовых образцов отношение $I_{D} / I_{G}$ обратно пропорционально $L_{a}$. В нашем случае эта зависимость выполняется для пленок, полученных при температуре осаждения выше $500^{\circ} \mathrm{C}$. Согласно данным работы [23], $L_{a}=C /\left(I_{D} / I_{G}\right)$, где $C$ - эмпирически определенный коэффициент, зависящий от длины волны возбуждающего лазера и равный 19.2 нм при $\lambda=532$ нм. Для пленок, полученных при температуре подложки 520 и $620^{\circ} \mathrm{C}$, величина $L_{a}$ составляет 3.6 и 7.2 нм соответственно.

На рис. 4 показаны спектры КРС исследуемых пленок, полученных при температуре подложки 320 и $620^{\circ} \mathrm{C}$, в области второго порядка (с одновременным участием в процессе рассеяния двух фононов) и результаты разложения их спектрального контура на отдельные линии. Линия $D+D^{\prime \prime}$ в области $2460 \mathrm{~cm}^{-1}$ появляется в результате рассеяния света с участием суперпозиции фонона, ответственного за $D$ полосу, и $L A$ фонона $\left(1100 \mathrm{~cm}^{-1}\right)$ [13]. Линия $2 D$ (на частоте $2690 \mathrm{~cm}^{-1}$ при температуре подложки $320^{\circ} \mathrm{C}$ и $2725 \mathrm{~cm}^{-1}$ при $620^{\circ} \mathrm{C}$ ) связана с резонансным рассеянием света с участием двух фононов с одинаковой энергией, но противоположным направлением импульса. Эта линия является обертоном линии $D$. Линия $D+D^{\prime}$ в области $2940 \mathrm{~cm}^{-1}$ возникает в результате двухфононного процесса рассеяния с участием дефекта решетки. Линия $2 D^{\prime}$ (на частоте $3215 \mathrm{~cm}^{-1}$ при температуре подложки $320^{\circ} \mathrm{C}$ и на $3229 \mathrm{~cm}^{-1}$ при $620^{\circ} \mathrm{C}$ ) является обертоном линии $D^{\prime}$ [24]. Присутствие этой линии в спектре КРС обусловлено процессом двойного резонанса, который является внутридолинным процессом с участием двух оптических фононов с противоположными направлениями импульса [13].

Так как полосы $2 D$ и $2 D^{\prime}$ обусловлены процессами рассеяния, для которых выполнение условия сохранения 

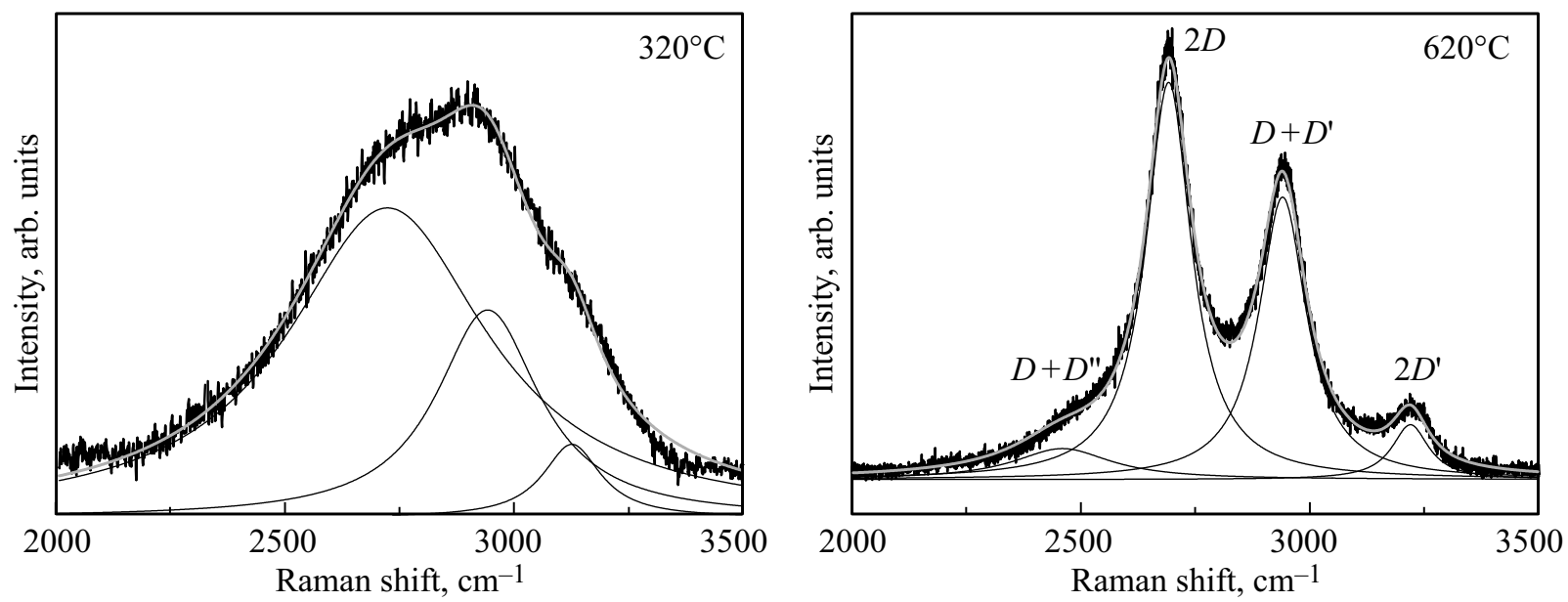

Pис. 4. Спектры КРС графитоподобных пленок в области второго порядка и результаты разложения их спектрального контура.

квазиимпульса не требует участия дефектов кристаллической решетки, эти линии присутствуют в спектрах КРС бездефектных графитовых материалов. Для двухфононного процесса рассеяния необходимо наличие дальнего порядка в графеновом слое [25,26]. Величина отношения интегральных интенсивностей $I_{2 D} / I_{G}$ характеризует степень дальнего порядка в пленке. Это отношение возрастает с 1.3 до 4.6 при увеличении температуры подложки с 320 до $620^{\circ} \mathrm{C}$, что свидетельствует об увеличении степени дальнего порядка в графеновых слоях. Сужение линии $2 D$ с $520 \mathrm{~cm}^{-1}$ при $320^{\circ} \mathrm{C}$ до $120 \mathrm{~cm}^{-1}$ при $620^{\circ} \mathrm{C}$ также может служить подтверждением улучшения структурного совершенства пленок с ростом температуры подложки. Линия $2 D$ не демонстрирует дуплетной структуры, что характерно для турбостратного графита, у которого отсутствует трехмерное упорядочение при сохранении упорядочения в графеновом слое [27].

Увеличение характерного размера кристаллитов $s p^{2}$ гибридизованного углерода в графитоподобных пленках в зависимости от температуры осаждения подтверждает также анализ спектров их оптической плотности, представленных на рис. 5. С увеличением температуры осаждения в спектрах оптического поглощения наблюдается сдвиг максимума поглощения, обусловленного межзонными $\pi-\pi^{*}$ электронными переходами, в область больших длин волн, от 215 нм для пленки, осажденной при $320^{\circ} \mathrm{C}$, до 250 нм для пленки, осажденной при $620^{\circ} \mathrm{C}$. Одновременно со смещением максимума поглощения также наблюдается увеличение интенсивности поглощения в видимой и ближней ИК-областях спектра. Подобные изменения ранее наблюдались в спектрах оптической плотности оксида графена при его обработке, которая приводила к увеличению среднего размера бездефектных участков $s p^{2}$-гибридизованного углерода [28]. Уменьшение оптической ширины запрещенной зоны вследствие увеличения количества и размера кристаллитов $s p^{2}$-гибридизованного углерода в аморфной матрице ранее предполагалось на основе теоретических расчетов [29] и впоследствии было продемонстрировано экспериментально в работе [30] при термической обработке пленок аморфного углерода. Таким образом, зарегистрированные изменения в спектрах оптического поглощения подтверждают предположение об уменьшении количества структурных дефектов при повышении температуры осаждения и указывают на рост характерного размера кристаллитов $s p^{2}$-гибридизованного углерода и уменьшение концентрации аморфного углерода в фазовом составе пленки.

Наблюдаемое изменение в соотношении графитовой и аморфной составляющих в фазовом составе приводит к изменению электронных свойств получаемых пленок, в частности их удельной проводимости. На рис. 6 представлена полученная при комнатной температуре зависимость удельной проводимости графитоподобных пленок от температуры подложки. С ростом температуры удельная проводимость увеличивается примерно в 150 раз.

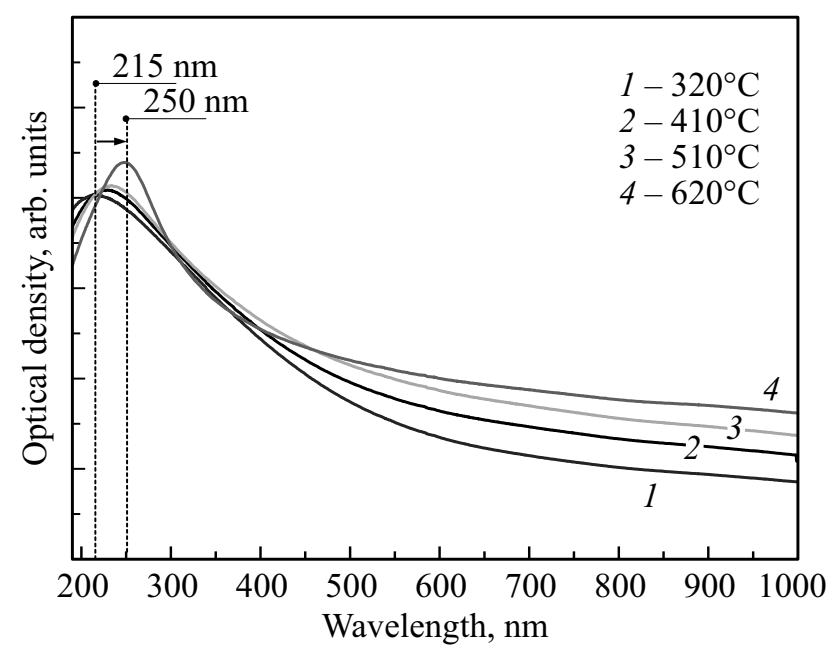

Рис. 5. Спектры оптической плотности графитоподобных пленок, осажденных при различных температурах подложки. 


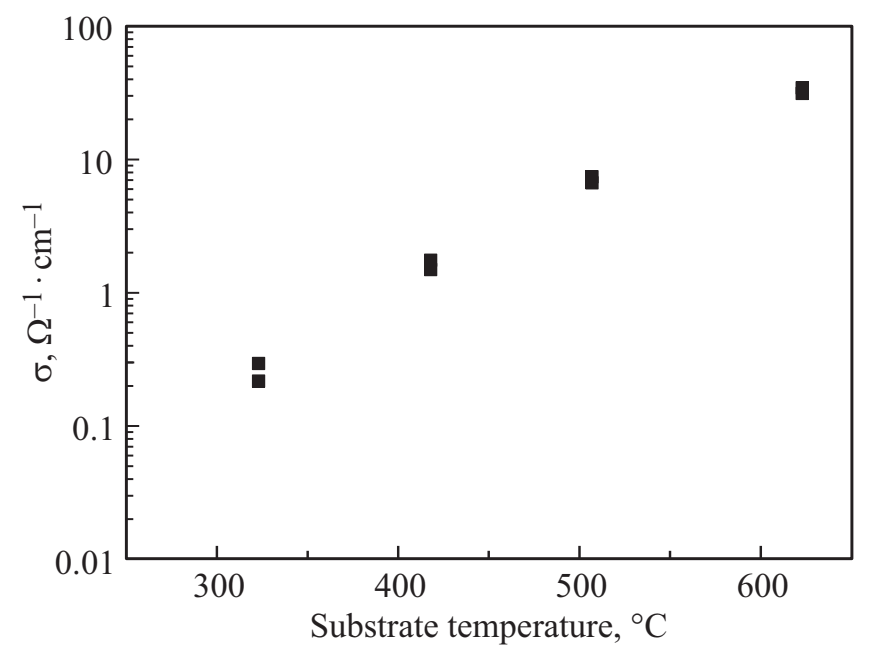

Рис. 6. Зависимость удельной проводимости графитоподобных пленок от температуры подложки.

Это может быть связано с тем, что в пленках графитоподобного углерода формируется сеть проводящих перколяционных каналов, образуемых массивом увеличивающихся в размерах кристаллитов $s p^{2}$-гибридизованного углерода. С ростом температуры подложки происходит рост размеров кристаллитов, а также их слияние с образованием больших фрагментов $s p^{2}$-гибридизованного углерода, а следовательно, снижением количества интерфейсов между кристаллитами. Совместно это обеспечивает увеличение удельной проводимости графитоподобных пленок. На электропроводность также влияет и концентрация вызывающих рассеяние носителей заряда дефектов в графеновых слоях, которая уменьшается с увеличением температуры осаждения, что приводит к росту удельной проводимости материала.

\section{4. Заключение}

Методом магнетронного распыления получены тонкие (40-100 нм) графитоподобные пленки на подложках из кремния и кристаллического кварца. Среднеквадратичная шероховатость полученных пленок увеличивается с 0.4 до 4.4 нм при изменении температуры подложки c 320 до $620^{\circ} \mathrm{C}$. Исследование пленок методом КРС продемонстрировало увеличение характерного размера кристаллитов, уменьшение концентрации структурных дефектов и содержания аморфного углерода в фазовом составе пленки с ростом температуры подложки. Трансформация структуры пленок от аморфной к нанокристаллической также подтверждается результатами исследований спектров оптического поглощения, в которых наблюдается смещение основного максимума поглощения в область больших длин волн и увеличение интенсивности поглощения в видимой и ближней ИК-области спектра. С ростом температуры подложки происходит увеличение удельной электропроводности пленок с $0.2 \mathrm{OM}^{-1} \cdot \mathrm{cm}^{-1}$ при $320^{\circ} \mathrm{C}$ до $30 \mathrm{OM}^{-1} \cdot \mathrm{cm}^{-1}$ при $620^{\circ} \mathrm{C}$.
Результаты исследования свойств полученных пленок позволяют рассматривать их в качестве перспективного материала для интеграции в конструкцию термоэлектрических преобразователей на основе чередующихся графитоподобных и выращенных методом CVD алмазных слоев. Используемые температуры осаждения графитоподобных слоев не будут приводить к ухудшению электрических и тепловых характеристик алмазных слоев в процессе создания преобразователей.

Авторы благодарят А.Я. Вуля за внимание к работе. Работа выполнена при финансовой поддержке РНФ (проект № 16-19-00075).

\section{Список литературы}

[1] Е.Д. Эйдельман, Ф.М. Шахов, А.Я. Вуль. Патент РФ на изобретение № 2628676. Заявка № 2016146445. Приоритет изобретения 25.11.2016. Дата государственной регистрации в Государственном реестре изобретений Российской Федерации 21.08.2017.

[2] E.D. Eidelman, A.Ya Vul'. J. Phys.: Condens. Matter, 19 (26), 266210 (2007).

[3] А.П. Мейлахс, Е.Д. Эйдельман. Письма ЖЭТФ, 100 (2), 89 (2014).

[4] Е.Д. Эйдельман. ФТП, 51 (7), 944 (2017).

[5] A.N. Obraztsov, A.V. Tyurnina, E.A. Obraztsova, A.A. Zolotukhin, B. Liu, K.C. Chin, A.T.S. Wee. Carbon, 46 (6), 963 (2008).

[6] Y. Miyasaka, A. Nakamura, J. Temmyo. Jpn. J. Appl. Phys., 50, 04DH12 (2011).

[7] J.J. Gracio, Q.H. Fan, J.C. Madaleno. J. Phys. D: Appl. Phys., 43 (37), 374017 (2010).

[8] М.В. Байдакова, А.Я. Вуль, В.Г. Голубев, С.А. Грудинкин, В.Г. Мелехин, Н.А. Феоктистов, А. Крюгер. ФТП, 36 (6), 651 (2002).

[9] S.A. Grudinkin, N.A. Feoktistov, A.V. Medvedev, K.V. Bogdanov, A.V. Baranov, A.Y. Vul, V.G. Golubev. J. Phys. D Appl. Phys., 45 (6), 062001 (2012).

[10] С.А. Грудинкин, Н.А. Феоктистов, К.В. Богданов, М.А. Баранов, А.В. Баранов, А.В. Федоров, В.Г. Голубев. ФТП, 48 (2), 283 (2014).

[11] A. Sadezky, H. Muckenhuber, H. Grothe, R. Niessner, U. Poschl. Carbon, 43 (8), 1731 (2005).

[12] A. Merlen, J.G. Buijnsters, C. Pardanaud. Coatings, 7 (10), 153 (2017).

[13] A.C. Ferrari, D.M. Basko. Nature Nanotech., 8(4), 235 (2013).

[14] S. Reich, C. Thomsen. Phil. Trans. Royal Soc. (London. A), 362, 2271 (2004).

[15] L.M. Malard, M.A.A. Pimenta, G. Dresselhaus, M.S. Dresselhaus. Phys. Reports, 473 (5), 51 (2009).

[16] A. Bianco, H.M. Cheng, T. Enoki, Y. Gogotsi, R.H. Hurt, N. Koratkar, T. Kyotani, M. Monthioux, C.R. Park, J.M.D. Tascon, J. Zhang. Carbon, 65, 1 (2013).

[17] T. Jawhari, A. Roid, J. Casado. Carbon, 33 (11), 1561 (1995).

[18] M. Couzi, J.-L. Bruneel, D. Talaga, L. Bokobza. Carbon, 107, 388 (2016).

[19] A.C. Ferrari, J. Robertson. Phys. Rev. B, 61 (20), 14095 (2000).

[20] A.C. Ferrari. Solid State Commun., 143 (1), 47 (2007). 
[21] O.A. Maslova, M.R. Ammar, G. Guimbretiere, J.-N. Rouzaud, P. Simon. Phys. Rev. B, 86 (13), 134205 (2012).

[22] F. Tuinstra, J.L. Koenig. J. Compos. Mater., 4 (4), 492 (1970).

[23] L.G. Cançado, K. Takai, T. Enoki, M. Endo, Y.A. Kim, H. Mizusaki, A. Jorio, L.N. Coelho, R. Magalhães-Paniago, M.A. Pimenta. Appl. Phys. Lett., 88 (16), 163106 (2006).

[24] R. Beams, L.G. Cancado, L. Novotny. J. Phys.: Condens. Matter, 27 (8), 083002 (2015).

[25] R.A. DiLeo, B.J. Landi, R.P. Raffaelle. J. Appl. Phys., 101 (6), 064307 (2007).

[26] S. Santangelo, G. Messina, G. Faggio, M. Lanza, C. Milone. J. Raman Spectrosc., 42 (4), 593 (2011).

[27] L.G. Cancado, K. Takai, T. Enoki, M. Endo, Y.A. Kim, H. Mizusaki, N.L. Speziali, A. Jorio, M.A. Pimenta. Carbon, 46 (2), 272 (2008).

[28] A.L. Stroyuk, N.S. Andryushina, N.D. Shcherban', V.G. Il'in, V.S. Efanov, I.B. Yanchuk, S.Ya. Kuchmii, V.D. Pokhodenko. Theor. Experiment. Chem., 48 (1), 2 (2012).

[29] J. Robertson. Phys. Rev. B, 35 (6), 2946 (1987).

[30] В.И. Иванов-Омский, А.В. Толмачев, С.Г. Ястребов. ФТП, 35 (2), 227 (2001).

Редактор А.Н. Смирнов

\section{Structure and properties of thin graphite-like films fabricated by magnetron sputtering}

A.Ya. Vinogradov' ${ }^{1}$, S.A. Grudinkin ${ }^{1}$, N.A. Besedina ${ }^{2}$, S.V. Koniakhin ${ }^{1,2}$, M.K. Rabchinskii ${ }^{1}$, E.D. Eidelman ${ }^{1,3}$, V.G. Golubev ${ }^{1}$

${ }^{1}$ Ioffe Institute,

194021 St. Petersburg, Russia

${ }^{2}$ St. Petersburg Academic University,

Russian Academy of Sciences,

194021 St. Petersburg, Russia

${ }^{3}$ St. Petersburg State

Chemical Pharmaceutical Academy, 197376 St. Petersburg, Russia

The structural, electrical, and optical properties of thin graphite-like films obtained on crystalline silicon and quartz by the magnetron sputtering technique at substrate temperatures in the range from 320 to $620^{\circ} \mathrm{C}$ have been studied. From an analysis of Raman spectroscopy data, it was found that as the substrate temperature increases, the characteristic size of the crystallites increases, the concentration of structural defects and the content of amorphous carbon decrease in the phase composition of graphite-like films. It was found that with an increase in the substrate temperature, the optical absorption spectra in the ultraviolet region of the spectrum exhibits a shift of the absorption intensity maximum toward longer wavelengths and an increase of the absorption in the visible and near infrared spectral range. The specific electric conductivity of films increases with an increase in the deposition temperature from $0.2 \mathrm{Ohm}^{-1} \cdot \mathrm{cm}^{-1}$ at $320^{\circ} \mathrm{C}$ to $30 \mathrm{Ohm}^{-1} \cdot \mathrm{cm}^{-1}$ at $620^{\circ} \mathrm{C}$. 